\title{
Physicians' opinion for 'new' genetic testing in Japan
}

\begin{abstract}
Takako Ohata $^{1}$, Atsushi Tsuchiya ${ }^{2}$, Maiko Watanabe $^{3}$, Tomohisa Sumida ${ }^{4}$ and Fumio Takada ${ }^{1}$
Recent advances in studies on human genetics have led to the use of genetic information in various applications. We conducted a survey to know the opinions of healthcare providers in Japan on new genetic testing services, such as direct-to-consumer (DTC) genetic testing. A total of 1124 general practitioners and 294 clinical geneticists replied to our questionnaire. Thirty-eight percent of the general practitioners and $68.4 \%$ of the clinical geneticists were aware of DTC genetic testing. Some physicians had gained information on this service through their patients or commercial activities of companies providing such services. General practitioners expected that DTC genetic testing would be convenient, promote preventive medicine, provide personalized services and would enable to maintain confidentiality of information. Clinical geneticists showed greater concern with regard to the reliability of the results, provision of information/counseling and the understanding of results. Awareness of DTC genetic testing enhances general practitioners' positive opinions of it. Although the market for DTC genetic testing in Japan may still be limited, it is possible that general practitioners will play a role in the provision of DTC genetic testing services in the future. On the basis of their knowledge and experience, clinical geneticists should provide information to both healthcare providers and to the public.
\end{abstract} Journal of Human Genetics (2009) 54, 203-208; doi:10.1038/jhg.2009.11; published online 20 March 2009

Keywords: commercialization; clinical utility; direct-to-consumer genetic testing; disease susceptibility; multifactorial inheritance

\section{INTRODUCTION}

Recent advances in studies on human genetics, particularly the completion of the Human Genome Project and the related innovation in analytical techniques have led to the use of genetic information in various applications. In this study, we report the results of a survey on the diversification and commercialization of health-related genetic tests, especially with regard to the direct-to-consumer (DTC) marketing or sales of genetic testing provided by the private sectors. In this survey, forensic tests, such as those related to paternity or personal identification, were excluded.

Diversification and commercialization of genetic testing Diversification of genetic testing implies that its purpose has been expanded from the diagnosis of disorders of single gene inheritance to the prediction of disease susceptibility or physical conditions that may develop in the future and to the classification of individuality and diversity not directly associated with diseases. With regard to the influence of these changes in clinical practice, it has been suggested that this kind of risk assessment by genetic information would become more generally provided in daily practices. ${ }^{1}$ Furthermore, the change in the use of genetic information in healthcare will require general practitioners who are not genetic specialists to contribute to the provision of genetic services. ${ }^{2,3}$

In addition, the commercialization of genetic testing services has progressed through the increased capacity of the private sector to translate the fruits of research into clinical applications or to provide technical support. Some problems have been encountered in the commercialization of genetic testing services, such as the provision of various genetic tests as commercial products and marketing and sales not only for healthcare providers but also for general consumers. The problem of commercialization of genetic testing services includes a possibility of premature implementation, which entails too early clinical application without adequate evaluation, and the risk of exaggerated advertising. Furthermore, once genetic testing appears in the market, it will be expected as if it is a standard practice. ${ }^{4}$

As a result of commercialization, the test provision route has been diversified. In recent years, genetic testing has been provided not only by geneticists but also by general practitioners, and DTC sales of genetic testing with a sample collection kit for consumer use has appeared outside the standard medical care setting. Although DTC sales of genetic testing may have potential benefits for consumers, for example, freedom of access, privacy and the use of a new technology in a more comfortable environment, ${ }^{5}$ some problems have been pointed out, such as the absence of guarantee of adequate counseling, the risk of being misled in the selection of tests and the interpretation of results, and the unclear clinical validity or usefulness of some commercially available tests. ${ }^{6-8}$ Therefore, critics have raised the opinion that genetic testing should be used only through healthcare providers. ${ }^{6}$ In addition, as the increase in DTC sale influences medical practice, an increase in the demand for care by general practitioners before and after genetic testing has been predicted. ${ }^{9}$

${ }^{1}$ Department of Medical Genetics, Kitasato University Graduate School of Medical Sciences, Sagamihara, Japan; ${ }^{2}$ Graduate School of Humanities and Sociology, The University of Tokyo, Bunkyo-ku, Tokyo, Japan; ${ }^{3}$ Department of Public Policy, Institute of Medical Science, The University of Tokyo, Minato-ku, Tokyo, Japan and ${ }^{4}$ Graduate School of Arts and Sciences, The University of Tokyo, Meguro-ku, Tokyo, Japan

Correspondence: Dr T Ohata, Department of Medical Genetics, Kitasato University Graduate School of Medical Sciences, Kitasato 1-15-1, Sagamihara 228-8555, Japan. E-mail: hatat@orange.ocn.ne.jp

Received 8 November 2008; revised 9 January 2009; accepted 9 January 2009; published online 20 March 2009 
In the United Kingdom, a company's direct sale of genetic testing and advice services regarding diet and health, which were based on their results had elicited discussion. In 2003, the Human Genetics Commission released Genes Direct, proposing reinforcement of the control of genetic tests directly sold to consumers. ${ }^{10}$ In the United States, as there is a market-based healthcare system, the risk of the premature and inappropriate use of genetic information has been reported to be high. ${ }^{11}$ With regard to DTC genetic testing services, the Genetic Alliance as an alliance of various genetic disease-associated organizations issued a written statement to the US Food and Drug Administration (FDA) on DTC sales in November 2005, voicing concern about the inadequate monitoring system for testing organizations, misleading advertising and the inadequate guarantee of consumers' choice with adequate consent. According to the national survey about awareness and the use of DTC nutrigenomic genetic testing conducted in the United States in 2006, 14\% of 5250 respondents were aware of these tests. ${ }^{12}$ In July 2006, concerning nutrigenomic tests directly sold to consumers, the Government Accountability Office commented that the information provided lacked scientific validity and ran the risk of misleading consumers. ${ }^{13}$ In the same year, the Federal Trade Commission issued the following consumer alerts: 'If considering using an at-home genetic test, talk to your doctor, healthcare practitioner, and a genetic counselor,' 'Before you do business with any company, check the privacy policy,' 'while most other home-use medical tests undergo FDA review to provide a reasonable assurance, no at-home genetic tests have been reviewed by the FDA. ${ }^{14}$ The American College of Medicine Genetics and the American Society of Human Genetics also released statements on DTC genetic testing respectively. ${ }^{15,16}$

\section{Present status in Japan and our points of issues}

In 2006, a survey for companies handling individuals' genetic information by the Japan Bioindustry Association showed the presence of 12 companies offering genetic tests for predisposition and 3 offering genetic tests for disease susceptibility. Whereas some companies are providing these tests through healthcare providers, some are providing genetic testing directly to consumers. In addition, as there are separate private companies involved in kit production, sales and analysis, the route of provision of genetic testing is very complicated.

Direct-to-consumer sales originally indicated the provision of this service outside the medical setting, but there are also private clinics selling genetic testing kits that are the same as DTC genetic testing. As some private clinics act as agencies for the sale of DTC genetic testing kits, dividing the provision of genetic testing into medical or nonmedical categories has become difficult.

In such a scenario, to clarify the problems that may arise in the genetic testing service in Japan in the future, we administered a questionnaire on physicians' awareness of and interest in DTC genetic testing as a symbol of commercialization of genetic testing. In particular, to clarify the problems associated with the future expansion of consultation on genetic testing with not only clinical geneticists but also general practitioners, both general practitioners and clinical geneticists were enrolled as subjects. Furthermore, the analysis was performed with a focus on the influences of their different genetic specialties on their opinions.

\section{MATERIALS AND METHODS}

\section{Study population and design}

The subjects consisted of members of the Medical Association of Kanagawa Prefecture and clinical geneticists. It is difficult to conduct this survey to physicians who were selected randomly among the member of Japan Medical
Association as general practitioners, so we chose Kanagawa Prefecture. It is the second large-scale prefecture and includes two government ordinance cities and several small-scale cities and rural area; therefore, the population characteristics of this prefecture are considered to be sufficiently diverse, making this prefecture suitable for the survey.

The Medical Association of Kanagawa Prefecture consists of physicians in Kanagawa Prefecture; $74 \%$ of these physicians were working in private clinics at the time of the survey, and only a few were clinical geneticists. Therefore, from all the members, excluding postgraduate trainees and those relieved from work, a total of 7528 members were enrolled in the general practitioner group. A Clinical Geneticist is a clinical physician who has Japanese Board of Medical Genetics. This board was given to physicians, including pediatricians, obstetricians, internists and so on, who have attended clinical genetics training for 3 years and passed the board examination provided by the Japan Society of Human Genetics and the Japanese Society for Genetic Counseling. A total of 503 clinical geneticists were enrolled in the clinical geneticist group.

The survey was performed by sending mail, and responses returned by mail were regarded as consent to cooperate in this survey. The survey was performed from September 18 to October 23, 2007.

The question items dealt with basic attributes, involvement in medical genetics and genetic services, opinions on the usefulness of new genetic tests recently provided, prediction of public demands for genetic testing, awareness of DTC genetic testing and information sources and opinions on the benefits and risks of DTC genetic testing.

\section{Procedure}

The survey protocol was reviewed and approved by the Ethical Committee, Kitasato University School of Medicine and Kitasato University Hospital (Approval No. B07-26).

\section{Data analysis}

Statistical analysis was performed using SPSS software for Windows ver. 11.0.

\section{RESULTS}

\section{Characteristics of respondents}

The number (rate) of responses was 1145 (15.2\%) and 294 (58.4\%) in the general practitioner and clinical geneticist groups, respectively. Table 1 shows the distribution of basic attributes in responders. On the basis of the responses to the questionnaire, the specialties of the subjects were reclassified as follows: internal medicine (including neurology, cardiology and gastroenterology), pediatrics, surgery (including general surgery, orthopedics, neurosurgery, urology and anesthesia), obstetrics and gynecology, medical genetics and others.

The percentages of subjects aged 60-69 years and those aged 70-79 years were higher in the general practitioner group, and more responders worked in larger medical institutions in the clinical geneticist group. According to the specialty, more doctors specializing in internal medicine were included in the general practitioner group, whereas doctors whose specialty was pediatrics and obstetrics/gynecology were frequently observed in the clinical geneticist group. In the general practitioner group, there was no physician working in the department of medical genetics, and only $3(0.3 \%)$ of 1145 responders were certified as clinical geneticists.

With regard to the involvement of the general practitioner group in medical genetics and genetic services, the subjects were asked about the degree of provision of diagnosis/treatment for genetic diseases and congenital abnormalities, provision or consultation for genetic testing or prenatal testing and genetic counseling in daily practice. Responses of 'rarely provide these services' and 'never provide these services' were given by 20.1 and $71.9 \%$ subjects, respectively; this suggested only a slight involvement of general practitioners in medical genetics and genetic services in daily practice. 
Degree of awareness of DTC genetic testing and information sources

Figure 1 shows the degree of awareness of DTC genetic testing in the general practitioner and clinical geneticist groups. The responses for using DTC genetic testing kits were as follows: 'I have actually performed testing' selected by only 0.5 and $1.0 \%$, respectively; 'I have seen these tests in stores or advertisements' selected by 5.5 and $20.6 \%$, respectively; and 'I have not seen such tests but have heard of

Table 1 Characteristics of respondents

\begin{tabular}{|c|c|c|c|c|}
\hline & \multicolumn{2}{|c|}{ General practitioner } & \multicolumn{2}{|c|}{ Clinical geneticist } \\
\hline & $n$ & (\%) & $\mathrm{n}$ & $(\%)$ \\
\hline \multicolumn{5}{|l|}{ Gender } \\
\hline Male & 929 & $(83.8)$ & 230 & (79.3) \\
\hline Female & 180 & $(16.2)$ & 60 & $(20.7)$ \\
\hline Total & 1109 & $(100.0)$ & 290 & (100.0) \\
\hline \multicolumn{5}{|l|}{ Age } \\
\hline$<40$ & 84 & $(7.4)$ & 35 & (11.9) \\
\hline $40-49$ & 291 & $(25.6)$ & 139 & $(47.3)$ \\
\hline $50-59$ & 339 & $(29.8)$ & 84 & $(28.6)$ \\
\hline $60-69$ & 191 & $(16.8)$ & 21 & $(7.1)$ \\
\hline Over 70 & 233 & $(20.5)$ & 15 & $(5.1)$ \\
\hline Total & 1138 & $(100.0)$ & 294 & $(100.0)$ \\
\hline \multicolumn{5}{|l|}{ Place of work } \\
\hline Clinic & 787 & $(69.5)$ & 23 & $(8.1)$ \\
\hline Hospital (except university hospital) & 273 & $(24.1)$ & 102 & $(35.8)$ \\
\hline University hospital & 57 & $(5.0)$ & 139 & $(48.8)$ \\
\hline Administrative agency & 10 & $(0.9)$ & 5 & $(1.8)$ \\
\hline Research institute & 5 & $(0.4)$ & 16 & $(5.6)$ \\
\hline Total & 1132 & $(100.0)$ & 285 & $(100.0)$ \\
\hline \multicolumn{5}{|l|}{ Specialty } \\
\hline Internal medicine & 432 & (38.9) & 44 & $(15.2)$ \\
\hline Pediatrics & 115 & $(10.4)$ & 101 & (34.9) \\
\hline Surgery & 209 & $(18.8)$ & 8 & $(2.8)$ \\
\hline Obstetrics and gynecology & 95 & $(8.6)$ & 73 & $(25.3)$ \\
\hline Medical genetics & 0 & $(0.0)$ & 34 & $(11.8)$ \\
\hline Other & 260 & $(23.4)$ & 29 & $(10.0)$ \\
\hline Total & 1111 & $(100.0)$ & 289 & $(100.0)$ \\
\hline
\end{tabular}

them' selected by 32.0 and $46.7 \%$, respectively. Subjects who selected the above three answers were considered to be aware of DTC genetic testing; thus, 38.0 and $68.4 \%$ subjects in the general practitioner and clinical geneticist groups, respectively, were aware of this kind of testing.

Table 2 shows the results of the question on information sources for DTC genetic testing of subjects aware of the test. In both groups, the main information sources were the Internet, TV/newspapers/magazines and scientific meetings/journals. The responses of the general practitioner and clinical geneticist groups were as follows: 'A patient sought a consultation with me' selected by $20(4.7 \%)$ and $12(6.0 \%)$, respectively; and 'A representative of the company selling test kits visited me' or 'A company provided information by telephone or mail' selected by $50(11.7 \%)$ and $14(7.0 \%)$, respectively (percentages in parentheses indicate subjects who were aware of DTC genetic testing). Thus, although to a small extent, consultation by patients and marketing activities of the companies influenced the awareness of the study subjects with regard to DTC genetic testing.

\section{Opinions on the benefits and risks of DTC genetic testing}

On the basis of previous surveys, the following items were considered as benefits of DTC genetic testing: 'This testing is useful because consumers staying far from medical institutions can undergo tests

Table 2 Information sources of direct-to-consumer genetic testing ${ }^{a}$

\begin{tabular}{|c|c|c|c|c|}
\hline & \multicolumn{2}{|c|}{ General practitioner } & \multicolumn{2}{|c|}{ Clinical geneticist } \\
\hline & $\mathrm{n}$ & $(\%)^{\mathrm{b}}$ & $\mathrm{n}$ & $(\%)^{b}$ \\
\hline Patient & 20 & $(4.7)$ & 12 & (6.0) \\
\hline Directly from a company & 11 & $(2.6)$ & 2 & $(1.0)$ \\
\hline Tel/DM from a company & 39 & $(9.1)$ & 12 & $(6.0)$ \\
\hline Internet & 90 & (21.0) & 86 & $(43.2)$ \\
\hline TV/newspapers/magazines & 243 & $(56.6)$ & 77 & $(38.7)$ \\
\hline Scientific meetings/journals & 129 & $(30.1)$ & 69 & $(34.7)$ \\
\hline Colleagues & 37 & $(8.6)$ & 35 & $(17.6)$ \\
\hline Other & 14 & (3.3) & 8 & (4.0) \\
\hline
\end{tabular}

Patient: a patient sought a consultation with me; directly from a company: a representative of the company selling test kits visited me; telephone/DM from a company: a company provided information by telephone or mail; Internet: I saw this type of testing on the Internet; TV/ newspapers/magazines: I saw it on TV or in a newspapers/magazines; scientific meetings/ journals: I heard about it in a scientific meeting or saw it in scientific journal; colleague: I heard about it from a colleague.

aultiple answers allowed.

bercentage of people who were aware of DTC genetic testing.

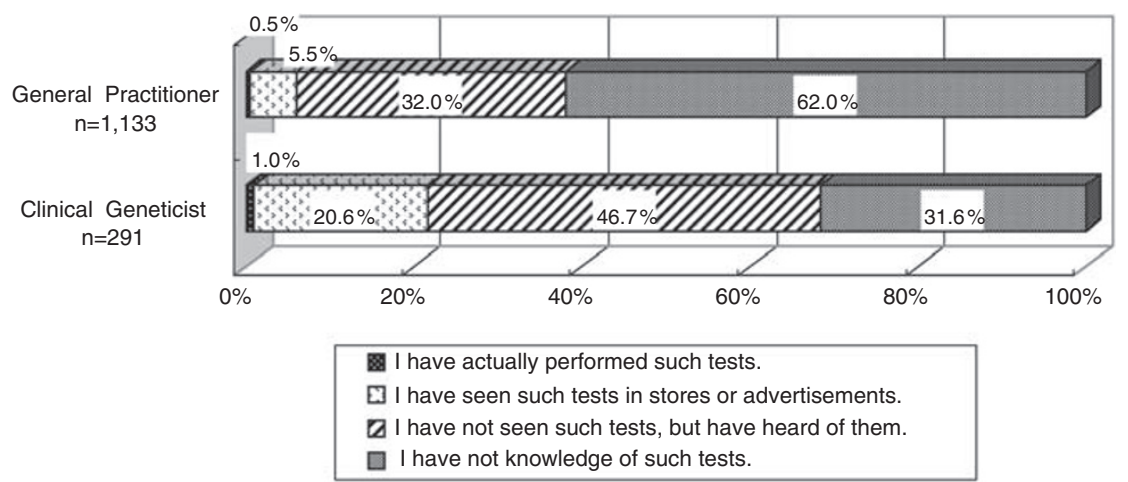

Figure 1 Comparison of awareness of DTC genetic testing. 'DTC genetic testing kits for the classification of predisposition to obesity or the prediction of susceptibility to hypertension/diabetes mellitus/osteoporosis have become commercially available. Do you know about the sale of such test kits?' 
(Convenience),' 'The promotion of preventive medicine by using convenient genetic tests can be expected (Promotion of preventive medicine),' 'This testing is useful because services according to the genetic makeup of each patient can be provided (Provision of personalized services)' and 'This testing is useful because consumers can undergo tests in private (Confidentiality of information).' The following seven items were considered as the risks of DTC genetic testing: 'The reliability of the results of genetic tests is questionable (Reliability of results)', 'I am concerned that the provision of adequate information and adequate counseling after the test (Provision of information/counseling)', 'I am concerned whether patients can correctly understand the test results (Understanding of results)', 'I am concerned about the appropriateness of advertisements (Advertising)',

Table 3 Benefits and risks of direct-to-consumer genetic testing

\begin{tabular}{|c|c|c|c|c|c|}
\hline & \multicolumn{2}{|c|}{$\begin{array}{c}\text { General } \\
\text { practitioner }\end{array}$} & \multicolumn{2}{|c|}{$\begin{array}{c}\text { Clinical } \\
\text { geneticist }\end{array}$} & \multirow[b]{2}{*}{$t$} \\
\hline & $\mathrm{n}$ & Score $e^{a}$ & $n$ & Score ${ }^{a}$ & \\
\hline \multicolumn{6}{|l|}{ Benefits } \\
\hline Convenience & 410 & 2.539 & 197 & 1.959 & $6.867 * * *$ \\
\hline Promotion of preventive medicine & 409 & 2.487 & 199 & 1.709 & $10.665^{* * *}$ \\
\hline Provision of personalized services & 407 & 2.484 & 198 & 1.778 & $9.748^{* * *}$ \\
\hline Confidentiality of information & 407 & 2.516 & 199 & 1.920 & $7.961 * * *$ \\
\hline \multicolumn{6}{|l|}{ Risks } \\
\hline Reliability of results & 410 & 2.768 & 197 & 3.137 & $-4.964 * * *$ \\
\hline Provision of information/counseling & 411 & 3.479 & 199 & 3.779 & $-5.786 * * *$ \\
\hline Understanding of results & 411 & 3.630 & 199 & 3.834 & $-4.525^{* * *}$ \\
\hline Advertising & 408 & 3.542 & 199 & 3.688 & $-2.727^{* *}$ \\
\hline Discrimination & 410 & 3.410 & 199 & 3.357 & 0.770 \\
\hline Spread of genetic determinism & 409 & 3.430 & 199 & 3.407 & 0.361 \\
\hline Information leakage & 410 & 3.456 & 199 & 3.332 & $1.892^{\dagger}$ \\
\hline
\end{tabular}

a Average score of people who were aware of DTC genetic testing.

${ }^{\dagger} P<0.1 ;{ }^{*} P<0.01 ;{ }^{* * *} P<0.001$.
'There is a possibility that the results will lead to discrimination in employment and insurance (Discrimination),' 'There is a possibility that beliefs such as genetic determinism will spread (Spread of genetic determinism), and 'I am concerned about the leaking of genetic information (Information leakage).. For each item, the subjects selected one of the following answers: 'Agree $=4$,' 'Somewhat agree $=3$,' 'Somewhat disagree $=2$ ' and 'Disagree $=1$ '. The mean score for each item in subjects who were aware of DTC genetic testing is shown in Table 3.

Among the benefits, the score for convenience was the highest in both the groups. Comparison between the two groups showed higher scores for all items (Convenience, Promotion of preventive medicine, Provision of personalized services and Confidentiality of information) in the general practitioner group than in the clinical geneticist group $(P<0.001)$. Among the risks, the concern was highest for 'Understanding of results,' followed in order by 'Advertisement' and 'Provision of information/counseling' in the general practitioner group; and in the clinical geneticist group, the concern was highest for 'Understanding of results', followed in order by 'Provision of information/ counseling' and 'Advertisement.' The clinical geneticist group showed greater concern over the reliability of results, provision of information/ counseling, understanding of results $(P<0.001$ for each item) and advertisement $(P<0.01)$ than the general practitioner group. The general practitioner group had slightly greater concern than the clinical practitioner group only for 'Information leakage' $(P<0.1)$.

In addition, trends in opinions on DTC genetic testing according to whether the respondents were aware of these tests were analyzed in both the groups. Table 4 compares the mean scores of the group that was aware or unaware of DTC genetic testing in both the groups.

Among the general practitioners, the aware group was more concerned about 'Promotion of preventive medicine' and 'Provision of personalized services' than the unaware group $(P<0.01)$, suggesting a positive impression of information generated by this testing in the former. Opinions on the risks were not different between the two groups. In contrast, in the clinical geneticists, however, opinions concerning the benefits of DTC genetic testing were not different

Table 4 Trends in opinions about DTC genetic testing according to whether they are aware of these tests

\begin{tabular}{|c|c|c|c|c|c|c|c|c|c|c|}
\hline & \multicolumn{5}{|c|}{ General practitioner } & \multicolumn{5}{|c|}{ Clinical geneticist } \\
\hline & \multicolumn{2}{|c|}{ Aware } & \multicolumn{2}{|c|}{ Unaware } & \multirow[b]{2}{*}{$t$} & \multicolumn{2}{|c|}{ Aware } & \multicolumn{2}{|c|}{ Unaware } & \multirow[b]{2}{*}{$t$} \\
\hline & $n$ & Score & $\mathrm{n}$ & Score & & $\mathrm{n}$ & Score & $\mathrm{n}$ & Score & \\
\hline \multicolumn{11}{|l|}{ Benefits } \\
\hline Convenience & 410 & 2.539 & 666 & 2.426 & $1.753^{\dagger}$ & 197 & 1.959 & 89 & 1.910 & 0.398 \\
\hline Promotion of preventive medicine & 409 & 2.487 & 667 & 2.327 & $2.614^{* *}$ & 199 & 1.709 & 88 & 1.784 & -0.651 \\
\hline Provision of personalized services & 407 & 2.484 & 664 & 2.319 & $2.742 * *$ & 198 & 1.778 & 88 & 1.773 & 0.048 \\
\hline Confidentiality of information & 407 & 2.516 & 665 & 2.462 & 0.892 & 199 & 1.920 & 88 & 1.955 & -0.296 \\
\hline \multicolumn{11}{|l|}{ Risks } \\
\hline Reliability of results & 410 & 2.768 & 659 & 2.851 & -1.539 & 197 & 3.137 & 86 & 3.256 & -1.069 \\
\hline Provision of information/counseling & 411 & 3.479 & 670 & 3.542 & -1.424 & 199 & 3.779 & 88 & 3.841 & -0.903 \\
\hline Understanding of results & 411 & 3.630 & 668 & 3.632 & -0.040 & 199 & 3.834 & 88 & 3.909 & -1.288 \\
\hline Advertisement & 408 & 3.542 & 663 & 3.597 & -1.335 & 199 & 3.688 & 88 & 3.830 & $-1.948^{\dagger}$ \\
\hline Discrimination & 410 & 3.410 & 666 & 3.420 & -0.223 & 199 & 3.357 & 89 & 3.618 & $-2.681^{* *}$ \\
\hline Spread of genetic determinism & 409 & 3.430 & 667 & 3.477 & -1.020 & 199 & 3.407 & 88 & 3.591 & $-1.897^{\dagger}$ \\
\hline Information leakage & 410 & 3.456 & 667 & 3.471 & 0.312 & 199 & 3.332 & 89 & 3.551 & $-2.239 *$ \\
\hline
\end{tabular}

${ }^{\dagger} P<0.1 ;{ }^{*} P<0.05 ;{ }^{*} P<0.01$. 
between the aware and unaware groups. However, the former group exhibited greater concern over 'Discrimination' $(P<0.01)$ and slightly greater concern about 'Information leakage' than the latter group $(P<0.05)$.

\section{DISCUSSION}

This is the first survey for physicians about DTC sales of genetic testing in Japan. Although it needs to reserve to conclude because of low response rate from general practitioners, some current problems and speculation in the near future in Japan are delivered by results of this survey.

In respondents of this survey, about 40 and $70 \%$ of subjects in the general practitioner and clinical geneticist groups, respectively, were aware of DTC genetic testing, whereas only $0.5 \%$ in the former group and $1.0 \%$ in the latter group had actually performed this testing. The number of healthcare providers actually handling DTC genetic testing in Japan may still be limited.

However, 50 subjects (11.7\% of those aware of DTC genetic testing) in the general practitioner group and 14 (7.0\% of those aware of it) in the clinical geneticist group had received information from marketing companies; furthermore, general practitioners who had been negligibly involved in practices of medical genetics, such as the diagnosis/ treatment of genetic diseases or congenital abnormalities and provision of genetic testing or counseling, were more concerned about the benefits of DTC genetic testing than clinical geneticists did. The awareness of this testing may enhance their positive opinion. These results may suggest that the same tests currently sold as DTC genetic testing will be available through healthcare providers, especially general practitioners, in the near future.

In Japan, current genetic testing services, including DTC sales, have several problems. First, there is no system to assess genetic testing of not only single-gene inheritance but also multifactorial inheritance. The important concepts to assess the benefit and risks of genetic testing are analytical validity, clinical validity, clinical utility and ethical social issues. ${ }^{17}$ Genetic testing for disease susceptibility and predisposition to predict the probability of diseases and physical conditions showing multifactorial inheritance are difficult to evaluate. ${ }^{18}$ However, the target of DTC genetic testing provided at present is just these diseases or conditions with multifactorial traits; assessment system of genetic testing should cover multifactorial inheritance. If diversification of genetic testing services progress without enough evaluation and several types of genetic testing for disease susceptibility or predisposition are provided both in medical settings and as DTC genetic testing, it is of concern that consumers may regard them as recognized standard practices.

The other question is whether every healthcare provider could appropriately cope with consultation by patients. Appropriate gatekeeping and monitoring by healthcare providers are important factors for genetic services, and healthcare providers are required to be appropriate gatekeepers. ${ }^{9}$ A previous survey of general practitioners showed that they had accepted their increasing role in genetic medicine, but did not have confidence in their ability to perform it, thereby suggesting the necessity for support by genetic specialists. ${ }^{19}$ In addition, the lack of knowledge on multifactorial inheritance ${ }^{20}$ or genetic testing ${ }^{21}$ among general practitioners, and anxiety about the practice of genetic counseling, has been reported. It is probable that in the future, genetic testing will be provided not only by clinical geneticists but also by general practitioners. In this study, clinical geneticists were more markedly anxious about the reliability of results of DTC sales of genetic testing, provision of information and counseling, understanding of results and advertisement than general practitioners were. These results can be explained on the basis of their experience in the clinical practice of medical genetics. To provide appropriate services, clinical geneticists are required to give information based on their knowledge and experience, and exchanges of opinions and discussions between general practitioners and clinical geneticists on their respective roles are necessary.

Several professional groups, for example, National Coalition for Health Professional Education in the United States or EuroGentest in Europe, have developed guidelines for genetics education and released core competencies in genetics for healthcare providers, ${ }^{22,23}$ and various strategies for education have been tried. ${ }^{24}$ These educational efforts could bring the effect that general practitioners and genetic professionals have much to learn from each other because the genetic professionals have better understanding of the primary-care perspective and general practitioners get more information about genetic contributors to disease. ${ }^{25}$

The Japan Society of Human Genetics published official comment on DTC genetic testing services in September 2008. In this comment, intervention by professionals with sufficient knowledge in the process, adhering to related guidelines, oversight by the governmental institution, education for general public, are required. Unfortunately, there is no government panel reviewing the issues of genetic testing and genetic services as the Human Genetic Commission in the United Kingdom, Secretary's Advisory Committee on Genetics, Health and Society (SACGHS) in the Unites States or Australian Law Reform Commission (ALRC) in Australia. It is necessary to construct an appropriate system for the evaluation and provision of genetic testing. On the other hand, not only regulation but also sharing current problems about medical genetic services with genetic professionals and general practitioners are so important.

Concerning the limitations of this study, as it was performed in the early stage of DTC sales, there is a possibility that problems actually present were not clarified. Further continuous observation of the problems associated with DTC genetic testing is necessary.

\section{ACKNOWLEDGEMENTS}

We acknowledge the respondents participating in this study. This work was a part of the Research Project on Ethical and Social problems caused by the commercial application and nonmedical use of genetic testing, supported by grants from the Ministry of Education, Culture, Sports, Science and Technology.

1 Collins, F. S. \& McKusick, V. A. Implications of the Human Genome Project for medical science. JAMA 285, 540-544 (2001).

2 Guttmacher, A. E., Jenkins, J. \& Uhlmann, W. R. Genomic medicine: who will practice it? A call to open arms. Am. J. Med. Genet. 106, 216-222 (2001).

3 Emery, J. \& Hayflick, S. The challenge of integrating genetic medicine into primary care. Br. Med. J. 322, 1027-1030 (2001).

4 Caulfield, T. The commercialization of human genetics: A Discussion of Issues Relevant to the Canadian Consumer. J. Consumer Policy 21, 483-526 (1998).

5 Williams-Jones, B. Re-framing the discussion: commercial genetic testing in Canada. Health Law J. 7, 49-67 (1999).

6 Gollust, S. E., Wilfond, B. S. \& Hull, S. C. Direct-to-consumer sales of genetic services on the Internet. Genet. Med. 5, 332-337 (2003).

7 Wasson, K., Cook, E. D. \& Helzlsouer, K. Direct-to-consumer online genetic testing and the four principles: an analysis of the ethical issues. Ethics Med. 22, 83-91 (2006).

8 Wolfberg, A. J. Genes on the Web-direct-to-consumer marketing of genetic testing. $N$. Engl. J. Med. 355, 543-545 (2006)

9 Caulfield, T. A. The informed gatekeeper?: a commentary on genetic tests, marketing pressure and the role of primary care physicians. Health. Law. Rev. 9, 14-18 (2001).

10 Human Genetics Commission. Genes direct: ensuring the effective oversight of genetic tests supplied directly to the public, http://www.hgc.gov.uk/UploadDocs/DocPub/ Document/genesdirect full.pdf.

11 Baird, P. A. Current challenges to appropriate clinical use of new genetic knowledge in different countries. Community Genet. 4, 12-17 (2001). 
12 Goddard, K. A., Moore, C., Ottman, D., Szegda, K. L., Bradley, L. \& Khoury, M. J. Awareness and use of direct-to-consumer nutrigenomic tests, United States, 2006. Genet. Med. 9, 510-517 (2007).

13 United States Government Accountability Office. NUTRIGENETIC TESTING: Tests Purchased from Four Web Sites Mislead Consumers, http://www.gao.gov/new.items/ d06977t.pdf.

14 Federal Trade Commission. At-Home Genetic Tests: A Healthy Dose of Skepticism May Be the Best Prescription, http://www.ftc.gov/bcp/edu/pubs/consumer/health/heaO2. shtm.

15 American College of Medicine Genetics Board of Directors. ACMG statement on directto-consumer genetic testing. Genet. Med. 6, 60 (2004).

16 Hudson, K., Javitt, G., Burke, W., Byers, P. \& with the American Society of Human Genetics Social Issues Committee ASHG Statement* on direct-to-consumer genetic testing in the United States. Am. J. Hum. Genet. 81, 635-637 (2007).

17 Secretary's Advisory Committee on Genetic Testing. Enhancing the Oversight of Genetic Tests: Recommendations of the SACGT (2000), http://oba.od.nih.gov/oba/sacgt/ reports/oversight_report.pdf.

18 McPherson, E. Genetic diagnosis and testing in clinical practice. Clin. Med. Res. 4, 123-129 (2006).
19 Emery, J., Watson, E., Rose, P. \& Andermann, A. A systematic review of the literature exploring the role of primary care in genetic services. Fam. Pract. 16, 426-445 (1999).

20 Bathurst, L. \& Huang, Q. R. A qualitative study of GPs' views on modern genetics. Aust. Fam. Physician 35, 462-464 (2006).

21 Baars, M. J., Henneman, L. \& Ten Kate, L. P. Deficiency of knowledge of genetics and genetic tests among general practitioners, gynecologists, and pediatricians: a global problem. Genet. Med. 7, 605-610 (2005).

22 Core Competency Working Group of the National Coalition for Health Professional Education in Genetics. Recommendations of core competencies in genetics essential for all health professionals. Genet. Med. 3, 155-159 (2001).

23 EuroGentest. Core competences in genetics for health professionals in Europe, http:// www.eurogentest.org/professionals/info/public/unit6/core_competences.xhtml.

24 Burke, W., Acheson, L., Botkin, J., Bridges, K., Davis, A., Evans, J. et al. Genetics in primary care: a USA faculty development initiative. Community Genet. 5, 138-146 (2002).

25 Burke, W. \& Emery, J. Genetics education for primary-care providers. Nat. Rev. Genet. 3, 561-566 (2002). 